\title{
Evolution of the serendipitous discovery of macrophage-lymphocyte interactions
}

\author{
Joost J. Oppenheim* \\ Laboratory of Molecular Immunology, National Cancer Institute, National Institutes of Health, Frederick, MD, USA \\ *Correspondence: oppenhej@mail.nih.gov \\ Edited by: \\ Kendall A. Smith, Weill Medical College of Cornell University, USA \\ Reviewed by: \\ Pietro Ghezzi, Brighton and Sussex Medical School, UK \\ Irina Caminschi, Burnet Institute, Australia
}

Keywords: lymphocytes, dendritic cells, macrophages, antigen presentation, chronic lymphocytic leukemic cells

\section{A commentary on}

The transformation of column-purified lymphocytes with nonspecific and specific antigenic stimuli

by Oppenheim JJ, Leventhal BG, Hersh EM. J Immunol (1968) 101:262-70.

This contribution to the project on the Living History of Immunology concerning "The Transformation of Column-Purified Lymphocytes with Non-specific and Specific Antigenic Stimuli," by Joost J. Oppenheim, Brigid G. Leventhal, and Evan M. Hersh represents another excellent example of research based on a serendipitous discovery snatched from the jaws of a failed project (1). Evan, Brigid, and I were all clinical associates at the NCI engaged in the care of patients with leukemia and solid tumors from 1962 until 1965. As a reward for our clinical efforts, we were given the opportunity to pursue laboratory research studies with one of the principal investigators for the last 2 years of our stay.

Following several false starts, I ended up in the laboratory of Dr. Jacqueline Wang Peng, who was an expert in studies of chromosome abnormalities caused by neoplastic changes and damage from chemotherapeutic and radiation treatments. Our chromosome analyses were frustrated by the failure of leukemic lymphocytes from chronic lymphocytic leukemia (CLL) patients to be activated to divide and develop metaphases that could be analyzed for chromosome breaks in response to a kidney bean extract known as phytohemagglutinin (PHA). Since the peripheral blood $(\mathrm{PB})$ of more advanced CLL patients contained high numbers of white blood cells (WBC) consisting entirely of lymphocytes, we decided as a control to purify the non-adherent lymphocytes present in normal PBWBC by eluting them off sterile glass bead or nylon fiber columns, which retained the adherent phagocytic neutrophils and monocytes.

After numerous mishaps and considerable practice, these columns yielded at least 98\% pure lymphocytes based on microscopic analysis. We were dismayed to find that these purified normal lymphocytes were also hyporesponsive to a variety of antigenic stimulants such as tetanus toxoid and streptolysin $\mathrm{O}$, but still showed normal proliferative response to the more potent polyclonal PHA stimulant. This was determined from the proportion of cells undergoing morphological blastogenesis and the uptake of tritiated thymidine. However, the purified lymphocytes in comparison with unpurified normal lymphocytes were also hyporesponsive to suboptimal doses of PHA. Of course, we were very concerned that the column procedure had damaged the cells, but we failed to observe any evidence of cell death based on trypan blue uptake. Furthermore, when cultured at a higher cell density, the lymphoproliferative response to antigens showed some recovery arguing against cell damage. This observation also suggested the possibility that the few residual contaminating non-lymphocytic cells might be interacting more effectively over the shorter distances at higher cell densities. We tested this idea by adding some unfractionated WBC back to the cultures of purified lymphocytes, which partially restored the lymphoproliferative response to antigens. A feeder layer consisting of WI-38 human embryonic fibroblasts had no restorative effect.

These results unfortunately failed to shed any light on the unresponsiveness of CLL cells. However, they pointed to the requirement for a cooperative interaction between phagocytic cells and lymphocytes. Based on the available literature, we proposed that macrophages were somehow facilitating the activation of lymphocytes to "transform" and proliferate. Evan Hersh and Jules Harris obtained convincing evidence in support of this hypothesis by restoring the lymphoproliferative responses by the addition of coverslips with adherent human macrophages to the cultures of purified lymphocytes (2).

I further pursued my immunological studies during a sabbatical year at the University of Birmingham in England from 1965 to 1966, where I learned to work with non-human species and showed that purified lymphocytes from guinea pig lymph nodes were also unresponsive to antigenic stimulants unless supplemented with some phagocytic cells. Upon returning to the Dental Institute at the National Institutes of Health (NIH), I was joined by a pediatrician, Dr. Robert Seeger in investigations of the role of macrophages in immunity. We were able to show that footpad injection of peritoneal macrophages from syngeneic guinea pigs after a brief exposure to antigens such as ovalbumin induced greater delayed hypersensitivity (DTH) reactions and were better at priming antibody responses than equal or higher doses of soluble antigens (3). Furthermore, antigens were taken up much less well by lymphocytes, thymocytes, and hepatoma cells than to macrophages and these cells were 
not immunogenic (4). Thus, macrophages could activate $\mathrm{T}$ lymphocytes to mediate DTH and prime B-cell antibody production. Bob Seeger and I also determined that peritoneal, alveolar, or $\mathrm{PB}$ macrophages obtained from either immune or nonimmune donors were all equally effective at priming immune responses (5). However, macrophages could not induce nonimmune lymphocytes to proliferate. Thus immune specificity and memory appeared to be a property of lymphocytes rather than macrophages.

In the course of our studies, Bob and I noticed that syngeneic macrophages were much more effective than allogeneic macrophages, but we did not pursue this issue. Alan Rosenthal thoroughly investigated the role of histocompatibility in this interaction. Alan Rosenthal and Ethan Shevach went on to show that the macrophage-lymphocyte interactions required MHC compatibility to be successful (6). They further determined, using alloantisera against $\mathrm{MHC}$ antigens, that macrophage MHC was necessary for $\mathrm{T}$ lymphocytic recognition of antigens (7). Of course, Ralph Steinman's discovery that dendritic cells (DC) contaminating the macrophage preparations were actually the most potent antigen presenting cells superseded our findings (8). However, I must confess that I found it difficult to accept the idea that the small contaminant population of DC rather than macrophages was responsible for antigen presentation, until this became incontrovertible based on the in vitro studies of Jacques Banchereau and his colleagues (9). They were able to produce large numbers of dendritic/Langerhans cells in vitro by culturing cord blood hematopoietic progenitor cells with a combination of granulocyte-macrophage colony stimulating factor and tumor necrosis factor. These cells had the morphology and phenotypic markers of DC and were very potent at presenting antigens and priming $\mathrm{T}$ lymphocytes.

Our serendipitous finding that $\mathrm{T}$ cells require accessory cells for antigen presentation was based on an initial desire to better understand the failure of lymphocytes from CLL patients to transform in response to stimulation. Other investigators have determined that CLL cells are usually monoclonal B lymphocytes that do not respond to $\mathrm{T}$ cell stimulants (10). This was followed by curiosity on our part to better understand the inability of purified normal peripheral human lymphocytes to respond to antigenic stimulation unless supplemented by macrophages. Our observations led other investigators to discover the crucial role of MHC in antigen presentation, antigen processing, and the outstanding capacity of DC to activate T cell-dependent immune responses. These consequent findings went beyond the scope of our imagination. In conclusion, our unexpected scientific findings clearly contributed in an unanticipated manner to a greater understanding of adaptive immunity and clearly illustrate the stepwise communal process of scientific progress.

\section{ACKNOWLEDGMENTS}

We are grateful for the constructive comments of Drs Arthur Hurwitz, Scott Durum, and Igal Gery; and also Ms. Sharon Livingstone and Mrs. Joan Boxell for their secretarial assistance with this essay.

\section{REFERENCES}

1. Oppenheim JJ, Leventhal BG, Hersh EM. The transformation of column-purified lymphocytes with nonspecific and specific antigenic stimuli. $J$ Immunol (1968) 101:262-70.

2. Hersh EM, Harris JE. Macrophage-lymphocyte interaction in the antigen-induced blastogenic response of human peripheral blood leukocytes. J Immunol (1968) 100:1184-94.

3. Seeger RC, Oppenheim JJ. Macrophage-bound antigens: I. Induction of delayed hypersensitivity and priming for production of serum antibodies in guinea pigs. J Immunol (1972) 109:244-54.
4. Seeger RC, Oppenheim JJ. Macrophage-bound antigens: II. Comparison of the immunogenicity of antigens bound to macrophages, lymphocytes, thymocytes and hepatoma cells. J Immunol (1972) 109:255-61.

5. Seeger RC, Oppenheim JJ. Synergistic interaction of macrophages and lymphocytes in antigeninduced transformation of lymphocytes. JExp Med (1970) 132:44-65. doi:10.1084/jem.132.1.44

6. Rosenthal AS, Shevach EM. Function of macrophages in antigen recognition by guinea pig T lymphocytes. J Exp Med (1973) 138:1194-212. doi:10.1084/jem.138.5.1194

7. Shevach EM, Rosenthal AS. Function of macrophages in antigen recognition by guinea pig T lymphocytes. J Exp Med (1973) 138:1213-29. doi:10.1084/jem.138.5.1213

8. Steinman RM, Cohn ZA. Identification of a novel cell type in peripheral lymphoid organs of mice. I. Morphology, quantitation, tissue distribution. J Exp Med (1973) 137:1142-62. doi:10.1084/jem. 137.5.1142

9. Caux C, Dezutter-Dambuyant C, Schmitt D, Banchereau J. GM-CSF and TNF- $\alpha$ cooperate in the generation of dendritic Langerhans cells. Nature (1992) 360:258-61. doi:10.1038/360258a0

10. Zhong Y, Byrd JC, Dubovsky JA. The B-cell receptor pathway: a critical component of healthy and malignant immune biology. Semin Hematol (2014) 51:206-18. doi:10.1053/j.seminhematol. 2014.05.007

Conflict of Interest Statement: The author declares that the research was conducted in the absence of any commercial or financial relationships that could be construed as a potential conflict of interest.

Received: 15 September 2014; paper pending published: 01 October 2014; accepted: 08 October 2014; published online: 27 October 2014.

Citation: Oppenheim JJ (2014) Evolution of the serendipitous discovery of macrophagelymphocyte interactions. Front. Immunol. 5:530. doi: 10.3389/fimmu.2014.00530

This article was submitted to T Cell Biology, a section of the journal Frontiers in Immunology.

Copyright (c) 2014 Oppenheim. This is an open-access article distributed under the terms of the Creative Commons Attribution License (CC BY). The use, distribution or reproduction in other forums is permitted, provided the original author(s) or licensor are credited and that the original publication in this journal is cited, in accordance with accepted academic practice. No use, distribution or reproduction is permitted which does not comply with these terms. 